\title{
Fractional Integral Operators Involving the Generalized Riemann Zeta Function with a Product of Certain Special Functions
}

\author{
V.B.L. Chaurasia ${ }^{1}$, Vinod Gill ${ }^{2}$ \\ ${ }^{I}$ Department of Mathematics, University of Rajasthan, Jaipur-302004, Rajasthan, India. \\ ${ }^{2}$ Department of Mathematics, Arya Institute of Engineering and Technology, Kukas, Jaipur-302028, Rajasthan,
} India.

Abstract: In this paper, we study two most general integral operators whose kernels are the product of the generalized Riemann Zeta function, a general class of polynomials and two multivariable H-function. First, we established the Mellin-transform of these operators. Then, due to general nature of the kernel, we can obtain a large number of Mellin-transforms involving product of several useful special functions.

Key Words: Fractional Integral Operators, Generalized Riemann Zeta function, General class of polynomials, Multivariable H-function, Mellin transform.

AMS Subject Classification: primary 26A33, 44A10, secondary 33 C60

\section{Introduction}

We shall study in this paper the fractional integral operators [1] defined by means of the following equations:

$$
\begin{aligned}
& { }_{x} R_{\left(\lambda_{r}\right)}^{\alpha, \beta}[f(x)]=p x^{-\alpha-p \beta-1} \int_{0}^{x} t^{\alpha}\left(x^{p}-t^{p}\right)^{\beta} \phi\left[z\left(\frac{t^{p}}{x^{p}}\right)^{\beta_{1}}, \mu, \delta\right] \\
& \cdot S_{n}^{m}\left[y\left(\frac{t^{p}}{x^{p}}\right)^{h}\left(1-\frac{t^{p}}{x^{p}}\right)^{k}\right] H\left[z_{1}\left(\frac{t^{p}}{x^{p}}\right)^{h_{1}}\left(1-\frac{t^{p}}{x^{p}}\right)^{k_{1}}, \ldots, z_{r}\left(\frac{t^{p}}{x^{p}}\right)^{h^{r}}\left(1-\frac{t^{p}}{x^{p}}\right)^{k_{r}}\right] \\
& \cdot H\left[\lambda_{1}\left(\frac{t^{p}}{x^{p}}\right)^{u}\left(1-\frac{t^{p}}{x^{p}}\right)^{v}, \ldots, \lambda_{r}\left(\frac{t^{p}}{x^{p}}\right)^{u}\left(1-\frac{t^{p}}{x^{p}}\right)^{v}\right] f(t) d t \\
& \mathrm{x}_{\left(\lambda_{\mathrm{r}}\right)}^{\alpha, \beta}[\mathrm{f}(\mathrm{x})]=\mathrm{px}^{\alpha} \int_{\mathrm{x}}^{\infty} \mathrm{t}^{-\alpha-\mathrm{p} \beta-1}\left(\mathrm{t}^{\mathrm{p}}-\mathrm{x}^{\mathrm{p}}\right)^{\beta} \phi\left[\mathrm{z}\left(\frac{\mathrm{x}^{\mathrm{p}}}{\mathrm{t}^{\mathrm{p}}}\right)^{\beta_{1}}, \mu, \delta\right] \\
& \cdot S_{n}^{m}\left[y\left(\frac{x^{p}}{t^{p}}\right)^{h}\left(1-\frac{x^{p}}{t^{p}}\right)^{k}\right] H\left[z_{1}\left(\frac{x^{p}}{t^{p}}\right)^{h_{1}}\left(1-\frac{x^{p}}{t^{p}}\right)^{k_{1}}, \ldots, z_{r}\left(\frac{x^{p}}{t^{p}}\right)^{h_{r}}\left(1-\frac{x^{p}}{t^{p}}\right)^{k_{r}}\right] \\
& \cdot H\left[\lambda_{1}\left(\frac{x^{p}}{t^{p}}\right)^{u}\left(1-\frac{x^{p}}{t^{p}}\right)^{v}, \ldots, \lambda_{r}\left(\frac{x^{p}}{t^{p}}\right)^{u}\left(1-\frac{x^{p}}{t^{p}}\right)^{v}\right] f(t) d t
\end{aligned}
$$

The operator defined by (1.1) exists under the following set of conditions:

(i) The quantities $\mathrm{h}_{1}, \ldots, \mathrm{h}_{\mathrm{r}}, \mathrm{k}_{1}, \ldots, \mathrm{k}_{\mathrm{r}}, \mathrm{u}, \mathrm{v}, \mathrm{h}, \mathrm{k}, \mathrm{p}$ are all positive (some of them may decrease to zero provided that the resulting operator has a meaning),

$$
\operatorname{Re}(\delta)>0,|z|<1
$$

$$
\operatorname{Re}(\alpha)+p v \sum_{i=1}^{r} \min _{1 \leq j \leq u}(i) \operatorname{Re}\left[d_{j}^{(i)} / \delta_{j}^{(i)}\right]+1>0,
$$


(iv)

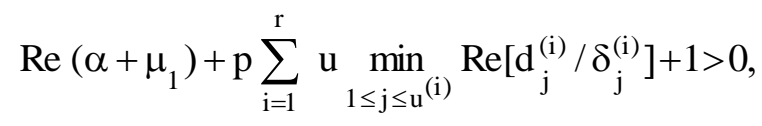

where

$$
f(x)=\left\{\begin{array}{l}
O\left(|x|^{\mu_{1}}\right),|x| \rightarrow 0 \\
O\left(|x|^{\nu} e^{-\mu_{2}|x|}\right),|x| \rightarrow \infty
\end{array}\right\}
$$

and the operator defined by (1.2) exists if

$$
\operatorname{Re}\left(\mu_{2}\right)>0 \text { or } \operatorname{Re}\left(\mu_{2}\right)=0
$$

$$
\operatorname{Re}(\alpha-v)+p u \sum_{i=1}^{r} \min _{1 \leq j \leq u^{(i)}} \operatorname{Re}\left[d_{j}^{(i)} / \delta_{j}^{(i)}\right]>0
$$

The generalized Riemann Zeta function $\phi[z, \mu, \delta]$ occurring in the equations (1.1) and (1.2) is defined in the following manner [2, p.27, eq.(1): 3, p.1075, eq. (9.550)]

$$
\phi[\mathrm{z}, \mu, \delta]=\sum_{\mathrm{n}=0}^{\infty}(\delta+\mathrm{n})^{-\mu} \mathrm{z}^{\mathrm{n}},|\mathrm{z}|<1, \operatorname{Re}(\delta)>0
$$

Equivalently, it has the integral expression

$$
\phi[\mathrm{z}, \mu, \delta]=\frac{1}{\Gamma(\mu)} \int_{0}^{\infty} \mathrm{t}^{\mu-1} \mathrm{e}^{-\delta \mathrm{t}}\left(1-\mathrm{z} \mathrm{e}^{-\mathrm{t}}\right)^{-1} \mathrm{dt}
$$

provided that $\operatorname{Re}(\delta)>0$ and either $|z| \leq 1, z \neq 1$ and $\operatorname{Re}(\mu)>0$ or $z=1$ and $\quad \operatorname{Re}(\mu)>1$.

The above mentioned function (1.3) is general in nature and yields a number of known functions as its special cases.

In particular, $\mu=1$ reduces the function $\phi[\mathrm{z}, 1, \delta]$ to hypergeometric function [2, p.30, eq.(10)]

$$
\phi[\mathrm{z}, 1, \delta]=\delta^{-1}{ }_{2} \mathrm{~F}_{1}[1, \delta ; 1+\delta ; \mathrm{z}]
$$

About four decades ago, Srivastava [4] defined a general class of polynomials

$$
\mathrm{S}_{\mathrm{n}}^{\mathrm{m}}[\mathrm{x}]=\sum_{\mathrm{k}=0}^{[\mathrm{n} / \mathrm{m}]} \frac{(-\mathrm{n})_{\mathrm{mk}}}{\mathrm{k} !} \mathrm{A}_{\mathrm{n}, \mathrm{k}} \mathrm{x}^{\mathrm{k}}, \mathrm{n}=0,1,2, \ldots
$$

and two interesting special cases of the polynomial are given in [5].

The series representation of the H-function of several complex variable studied by Olkha and Chaurasia [6] is given as follows:

$$
\begin{aligned}
& H\left[z_{1}, \ldots, z_{r}\right]=\sum_{m_{i}=1}^{u^{(i)}} \sum_{n_{i}=0}^{\infty} \frac{\prod_{j=1}^{\lambda} \Gamma\left(1-a_{j}+\sum_{i=1}^{r} \theta_{j}^{(i)} U_{i}\right)}{\prod_{j=\lambda+1}^{A} \Gamma\left(a_{j}-\sum_{i=1}^{r} \theta_{j}^{(i)} U_{i}\right) \prod_{j=1}^{C} \Gamma\left(1-c_{j}+\sum_{i=1}^{r} \psi_{j}^{(i)} U_{i}\right)} \\
& \frac{\prod_{\substack{j=1 \\
j \neq m_{i}}}^{u^{(i)}} \Gamma\left(d_{j}^{(i)}-\delta_{j}^{(i)} U_{i}\right) \prod_{j=1}^{v^{(i)}} \Gamma\left(1-b_{j}^{(i)}+\phi_{j}^{(i)} U_{i}\right) \prod_{i=1}^{r}\left(z_{i}\right)^{U_{i}}(-1)^{i=1} \sum_{j}^{r}\left(r_{i}\right)}{\prod_{j=u^{(i)}+1}^{D^{(i)}} \Gamma\left(1-d_{j}^{(i)}+\delta_{j}^{(i)} U_{i}\right) \prod_{j=v^{(i)}+1}^{B^{(i)}} \Gamma\left(b_{j}^{(i)}-\phi_{j}^{(i)} U_{i}\right) \prod_{i=1}^{r}\left(\delta_{m_{i}}^{(i)} n_{i} !\right)}
\end{aligned}
$$

where

$$
U_{i}=\frac{d_{m_{i}}^{(i)}+n_{i}}{\delta_{m_{i}}^{(i)}}, i=1, \ldots, r
$$

which is valid under the following condition

$$
\delta_{m_{i}}^{(i)}\left[d_{j}^{(i)}+p_{i}\right] \neq \delta_{j}^{(i)}\left[d_{m_{i}}^{(i)}+n_{i}\right]
$$


for $\mathrm{j} \neq \mathrm{m}_{\mathrm{i}}, \mathrm{m}_{\mathrm{i}}=1, \ldots, \mathrm{u}^{(\mathrm{i})} ; \mathrm{p}_{\mathrm{i}}, \mathrm{n}_{\mathrm{i}}=0,1,2, \ldots ; \mathrm{z}_{\mathrm{i}} \neq 0$

$$
\nabla_{\mathrm{i}}=\sum_{\mathrm{j}=1}^{\mathrm{A}} \theta_{\mathrm{j}}^{(\mathrm{i})}-\sum_{\mathrm{j}=1}^{\mathrm{C}} \psi_{\mathrm{j}}^{(\mathrm{i})}+\sum_{\mathrm{j}=1}^{\mathrm{B}^{(\mathrm{i})}} \phi_{\mathrm{j}}^{(\mathrm{i})}-\sum_{\mathrm{j}=1}^{\mathrm{D}^{(\mathrm{i})}} \delta_{\mathrm{j}}^{(\mathrm{i})}<0, \forall \mathrm{i}=1, \ldots, \mathrm{r}
$$

The multivariable H-function due to Srivastava and Panda [7] will be required in the proof.

\section{Mellin-Transforms}

The well-known Mellin-transform of the function $\mathrm{f}(\mathrm{x})$ defined by the following equation

$$
F(s)=M\{f(x): s\}=\int_{0}^{\infty} x^{s-1} f(x) d x,
$$

where $\operatorname{Re}\left(s+\mu_{1}\right)>0$ and $\operatorname{Re}\left(\mu_{2}\right)=0$ or $\operatorname{Re}\left(\mu_{2}\right)=0, \operatorname{Re}(v-s)>0$.

Now we shall establish the following Theorems

\section{Main Results}

Theorem - 1: If $M\left[{ }_{x} R_{\left(\lambda_{r}\right)}^{\alpha, \beta}\{f(x)\}: s\right]$ exists, then

$$
\mathrm{M}\left[\mathrm{R}_{\left(\lambda_{\mathrm{r}}\right)}^{\alpha, \beta}\{\mathrm{f}(\mathrm{x})\}: \mathrm{s}\right]=\mathrm{M}\{\mathrm{f}(\mathrm{x}): \mathrm{s}\} \phi_{1}(\mathrm{~s}) \text {. }
$$

Theorem-2: If $M\left[{ }_{x} W_{\left(\lambda_{r}\right)}^{\alpha, \beta}\{f(x)\}: s\right]$ exists, then

$$
\mathrm{M}\left[\mathrm{W}_{\left(\lambda_{\mathrm{r}}\right)}^{\alpha, \beta}\{\mathrm{f}(\mathrm{x})\}: \mathrm{s}\right]=\mathrm{M}\{\mathrm{f}(\mathrm{x}): \mathrm{s}\} \phi_{1}(1-\mathrm{s}) .
$$

where

$$
\begin{aligned}
& \phi_{1}(\mathrm{~s})=\Delta_{1} \Delta_{1}^{\prime} \Delta_{2} \mathrm{H}_{\mathrm{A}+2, \mathrm{C}+1:\left(\mathrm{B}^{\prime}, \mathrm{D}^{\prime}\right) ; \ldots ;\left(\mathrm{B}^{(\mathrm{r})}, \mathrm{D}^{(\mathrm{r})}\right)}^{0, \lambda+2 \quad:\left(\mathrm{u}^{\prime}, \mathrm{v}^{\prime}\right) ; \ldots ;\left(\mathrm{u}^{(\mathrm{r})}, \mathrm{v}^{(\mathrm{r})}\right)}
\end{aligned}
$$

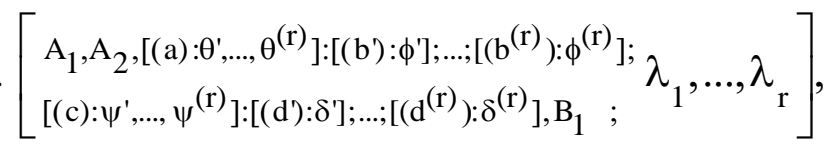

where

$$
\begin{aligned}
& \Delta_{1}=\sum_{\mathrm{n}_{1}=0}^{\infty}\left(\delta+\mathrm{n}_{1}\right)^{-\mu} \mathrm{z}^{\mathrm{n}_{1}} \\
& \Delta_{1}^{\prime}=\sum_{\ell=0}^{[\mathrm{n} / \mathrm{m}]} \frac{(-\mathrm{n}){ }_{\mathrm{m} \ell}}{\ell !} \mathrm{A}_{\mathrm{n}, \ell} \mathrm{y}^{\ell} \\
& \Delta_{2}=\sum_{\mathrm{e}_{\mathrm{i}}=0}^{\mathrm{m}_{\mathrm{i}}} \sum_{\mathrm{f}_{\mathrm{i}}=0}^{\infty} \phi_{1} \phi_{2} \frac{\left.\prod_{\mathrm{i}=1}^{\mathrm{r}}\left(\mathrm{z}_{\mathrm{i}}\right)^{\mathrm{U}_{\mathrm{i}}}(-1)^{\mathrm{i}=1} \operatorname{lf}_{\mathrm{i}}^{\mathrm{r}}\right)}{\prod_{\mathrm{i}=1}^{\mathrm{r}}\left[\mathrm{W}_{\mathrm{e}_{\mathrm{i}}}^{(\mathrm{i})} \mathrm{f}_{\mathrm{i}} !\right]}
\end{aligned}
$$

Here

$$
\phi_{1}=\frac{\prod_{j=1}^{\lambda_{1}} \Gamma\left(1-e_{j}+\sum_{i=1}^{r} \alpha_{j}^{(i)} U_{i}\right)}{\prod_{j=\lambda_{1}+1}^{p} \Gamma\left(e_{j}-\sum_{i=1}^{r} \alpha_{j}^{(i)} U_{i}\right) \prod_{j=1}^{q} \Gamma\left(1-f_{j}+\sum_{i=1}^{r} \beta_{j}^{(i)} U_{i}\right)},
$$




$$
\begin{aligned}
& \phi_{2}=\frac{\prod_{j=1}^{\mathrm{m}_{(i)}} \Gamma\left(\mathrm{F}_{\mathrm{j}}^{(\mathrm{i})}-\mathrm{W}_{\mathrm{j}}^{(\mathrm{i})} \mathrm{U}_{\mathrm{i}}\right) \prod_{\mathrm{j}=1}^{\mathrm{n}_{(\mathrm{i})}} \Gamma\left(1-\mathrm{E}_{\mathrm{j}}^{(\mathrm{i})}+\gamma_{\mathrm{j}}^{(\mathrm{i})} \mathrm{U}_{\mathrm{i}}\right)}{\prod_{\mathrm{j}=\mathrm{m}_{(\mathrm{i})}+1}^{\mathrm{q}_{\mathrm{i}}} \Gamma\left(1-\mathrm{F}_{\mathrm{j}}^{(\mathrm{i})}+\mathrm{W}_{\mathrm{j}}^{(\mathrm{i})} \mathrm{U}_{\mathrm{i}}\right) \prod_{\mathrm{j}=\mathrm{n}_{(\mathrm{i})}+1}^{\mathrm{p}_{\mathrm{i}}} \Gamma\left(\mathrm{E}_{\mathrm{j}}^{(\mathrm{i})}-\gamma_{\mathrm{j}}^{(\mathrm{i})} \mathrm{U}_{\mathrm{i}}\right)}, \quad \forall \mathrm{i}=1, \ldots, \mathrm{r} \\
& \left.\mathrm{A}_{1}=\left[\begin{array}{l}
1-\mathrm{s}+\alpha+\mathrm{p} \sum_{\mathrm{i}=1}^{\mathrm{r}} \mathrm{h}_{\mathrm{i}} \mathrm{U}_{\mathrm{i}}+\left(\mathrm{n}_{1} \beta_{1}+\mathrm{h} \ell\right) \mathrm{p} \\
\mathrm{p}
\end{array}\right], \mathrm{u}, \ldots, \mathrm{u}\right] \\
& \mathrm{A}_{2}=\left[-\beta-\sum_{\mathrm{i}=1}^{\mathrm{r}} \mathrm{k}_{\mathrm{i}} \mathrm{U}_{\mathrm{i}}-\mathrm{k} \ell ; \mathrm{v}, \ldots, \mathrm{v}\right], \\
& \mathrm{B}_{1}=\left[-\beta-\sum_{\mathrm{i}=1}^{\mathrm{r}}\left(\mathrm{h}_{\mathrm{i}}+\mathrm{k}_{\mathrm{i}}\right) \mathrm{U}_{\mathrm{i}}-\mathrm{n}_{1} \beta_{1}(\mathrm{~h}+\mathrm{k}) \ell-\frac{1-\mathrm{s}+\alpha}{\mathrm{p}} ; \mathrm{u}+\mathrm{v}, \ldots, \mathrm{u}+\mathrm{v}\right],
\end{aligned}
$$

The conditions under which the above Theorems are valid can easily be obtained from the conditions (i) through (vi) and (1.3).

Proof. To prove Theorem 1, first we write the Mellin-transform of the R-operator with the help of the equation (2.1), then we change the order of $t$ and $x$-integrals. Now we express the series expansions for the function $\phi[\mathrm{z}, \mu, \delta]$ and the polynomial $\mathrm{S}_{\mathrm{n}}^{\mathrm{m}}[\mathrm{x}]$ with the help of (1.3) and (1.6) respectively, express one multivariable $\mathrm{H}$ function in series form using (1.7)and another multivariable $\mathrm{H}$-function in terms of Mellin-Barnes contour integrals [7]. Then changing the order of integration and summations and evaluate the $\mathrm{x}$-integral with the help of a known result [2, p.10, eq. (17)] and reinterpreting the resulting Mellin-Barnes contour integrals in terms of the multivariable $\mathrm{H}$-function, we easily arrive at the desired Theorem.

Theorem 2 is established with the help of (1.2) and (2.1) and proceeding on similar lines as indicated in the proof of Theorem 1 and make use of another well-known result [3, p.295, eq.(3)].

\section{Special Cases}

On specializing the parameters involved in (1.1) and (1.2), we derive some interesting special cases, which will be useful in the literature on applied Mathematics.

(I) If we set $\mathrm{n}=0$ in (2.2), then the polynomial $\mathrm{S}_{0}^{\mathrm{m}}[\mathrm{x}]$ will reduce to $\mathrm{A}_{0,0}$, which can be taken as unity without loss of generality, and we obtain the following result.

$$
M\left[R_{\left(\lambda_{r}\right)}^{\alpha, \beta}\{f(x)\}: s\right]=M\{f(x): s\} \phi_{2}(s) .
$$

where

$$
\begin{aligned}
& \phi_{2}(\mathrm{~s})=\Delta_{1} \Delta_{2} \mathrm{H}_{\mathrm{A}+2, \mathrm{C}+1:\left(\mathrm{B}^{\prime}, \mathrm{D}\right) ; \ldots ;\left(\mathrm{B}^{(\mathrm{r})}, \mathrm{D}^{(\mathrm{r})}\right)}^{0, \lambda+2 \quad:\left(\mathrm{u}^{\prime}, \mathrm{v}^{\prime}\right) ; \ldots ;\left(\mathrm{u}^{(\mathrm{r})}, \mathrm{v}^{(\mathrm{r})}\right)}
\end{aligned}
$$

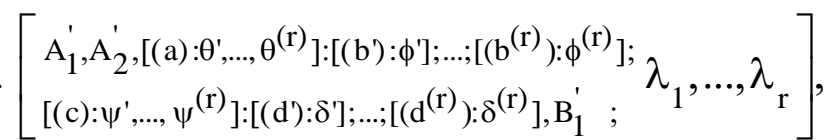

where

$$
\begin{aligned}
& A_{1}^{\prime}=\left[1-\frac{1-\mathrm{s}+\alpha+\mathrm{p} \sum_{\mathrm{i}=1}^{\mathrm{r}} \mathrm{h}_{\mathrm{i}} \mathrm{U}_{\mathrm{i}}+\mathrm{n}_{1} \beta_{1} \mathrm{p}}{\mathrm{p}} ; \mathrm{u}, \ldots, \mathrm{u}\right], \\
& \mathrm{A}_{2}^{\prime}=\left[-\beta-\sum_{\mathrm{i}=1}^{\mathrm{r}} \mathrm{k}_{\mathrm{i}} \mathrm{U}_{\mathrm{i}} ; \mathrm{v}, \ldots, \mathrm{v}\right],
\end{aligned}
$$




$$
\mathrm{B}_{1}^{\prime}=\left[-\beta-\sum_{\mathrm{i}=1}^{\mathrm{r}}\left(\mathrm{h}_{\mathrm{i}}+\mathrm{k}_{\mathrm{i}}\right) \mathrm{U}_{\mathrm{i}}-\mathrm{n}_{1} \beta_{1}-\frac{1-\mathrm{s}+\alpha}{\mathrm{p}} ; \mathrm{u}+\mathrm{v}, \ldots, \mathrm{u}+\mathrm{v}\right],
$$

This result is valid under conditions obtainable from those given earlier for (1.1).

If we set $\mathrm{n}=0$ in (2.3), then similar change will be obtained.

II. On giving suitable values to the parameters involved in polynomial in main theorem (i.e. Theorem 1 and Theorem 2), a number of interesting cases can be derived as special cases.

III. If we set $\mu=1$ in (2.2), then the function $\phi[z, 1, \delta]$ reduces to hypergeometric function [2, p.30, Eq.(10)] i.e. $\delta^{-1}{ }_{2} \mathrm{~F}_{1}[1, \delta ; 1+\delta ; \mathrm{z}]$ and we obtain the following result

$$
M\left[R_{x}^{\alpha, \beta}\{f(x)\}: s\right]=M\{f(x): s\} \phi_{3}(s) .
$$

where

$$
\begin{aligned}
& \phi_{3}(\mathrm{~s})=\Delta_{1}^{\prime \prime} \Delta_{1}^{\prime} \Delta_{2} \mathrm{H}_{\mathrm{A}+2, \mathrm{C}+1:\left(\mathrm{B}^{\prime}, \mathrm{D}^{\prime}\right) ; \ldots ;\left(\mathrm{B}^{(\mathrm{r})}, \mathrm{D}^{(\mathrm{r})}\right)}^{0, \lambda+2 \quad:\left(\mathrm{u}^{\prime}, \mathrm{v}^{\prime}\right) ; \ldots ;\left(\mathrm{u}^{(\mathrm{r})}, \mathrm{v}^{(\mathrm{r})}\right)}
\end{aligned}
$$

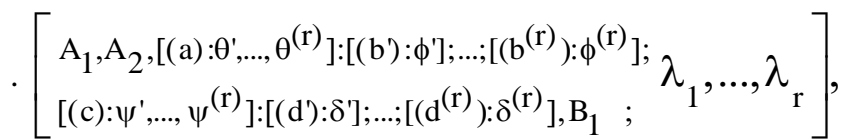

where

$$
\Delta_{1}^{\prime \prime}=\sum_{\mathrm{n}_{1}=0}^{\infty} \frac{1}{\delta+\mathrm{n}_{1}} \mathrm{z}^{\mathrm{n}_{1}}
$$

This result is valid under conditions obtainable from those given earlier for (1.1).

If we set $\mu=1$ in (2.3), then similar changes will be observed.

IV. On giving suitable values to the parameters of multivariable $\mathrm{H}$-function, we get the operators due to Parashar [8, p.141], Kalla and Saxena [9,p.231], Erdélyi [10,p.293] and Kober [11, p.193] and then a number of interesting cases can be derived as special cases of (2.2) and (2.3).

\section{References}

[1] R. Patni: A study of generalized hypergeometric polynomials and special functions of several complex variables with their applications, Ph.D. Thesis, Univ. of Rajasthan, Jaipur, India, 2001.

[2] A. Erdélyi et al.: Higher Transcendental Functions, Vol.1, McGraw-Hill, New York, 1953.

[3] I.S. Gradshteyn and I.M. Ryzhik: Table of integrals, Series and products, Academic Press, New York and London, 1965.

[4] H.M. Srivastava: A contour integral involving Fox's H-function. Indian J. Math. 14, 1-6 (1972).

[5] H.M. Srivastava and N.P. Singh: The integration of certain products of the multivariable H-function with a general class of polynomials, Rendiconti del Circolo Mathematics di Palermo, 32, 157-187 (1983).

[6] G.S. Olkha and V.B.L. Chaurasia: Series representation for the H-function of general complex variables, Math. Edu., 19: 1, 38-40 (1985).

[7] H.M. Srivastva and R. Panda: Some bilateral generating function for a class of generalized hypergeometeric polynomials, J. Reine. Angew. Math., 283/284, 265-274 (1976).

[8] B.P. Parashar: Domain and range of fractional integration operators, Math. Japan. 12, 141-145 (1968)

[9] S.L. Kalla and R.K. Saxena: Integral operators involving hypergeometric functions, Math. Zeitschr 108, 231-234 (1969).

[10] A. Erdélyi: On fractional integration and its Application to the theory of Hankel transforms, Quart. J. Math. Oxford Ser. 2, 293-303 (1940).

[11] H. Kober: On fractional integrals and derivatives, Quart. J. Math. Oxford Ser. 11, 193-211 (1940). 